\title{
Linaria genistifolia (L.) Miller ssp. confertiflora (Boiss.) Davis ÜZERINNDE ANATOMİK BİR ÇALIŞMA*
}

AN INVESTIGATION ON THE ANATOMY OF Linaria genistifolia (L.) Miller ssp. confertiflora (Boiss.) Davis

\begin{abstract}
Nurgün ERDEMOĞLU** Funda BİNGÖL** Bilge ŞENER**
Gazi Üniversitesi Eczacılık Fakültesi Farmakognozi Anabilim Dalı, 06330 Hipodrom /Ankara

\section{ÖZET}

Linaria genistifolia (L.) Miller ssp. confertiflora (Boiss.) Davis, memleketimizde geniş yayılışa sahip ve halk ilacı olarak kullanılan bir bitkidir. Bu çalışmada bitkinin anatomik özellikleri incelenmiştir.

Anahtar kelimeler: Scrophulariaceae, Linaria genistifolia (L) Miller ssp. confertiflora (Boiss.) Davis, Anatomi

\section{SUMMARY}

Linaria genistifolia (L.) Miller ssp. confertiflora (Boiss.) Davis, is widely spread in Turkey and used as a folk medicine. In this study, anatomical properties of the plant are investigated.

Key Words: Scrophulariaceae, Linaria genistifolia (L.) Miller ssp. confertiflora (Boiss.) Davis, Anatomy, Toadflax

\section{GİRİŞ}

Scrophulariaceae familyasına ait bir cins olan Linaria Miller çok yıllık otsu bir bitkidir. Yeryüzünde 150 kadar tür ile temsil edilen cinsin ülkemizde 9 tanesi endemik olmak üzere, 20 türü ve 12 alt türü bulunmaktadır (1).

* Bu araştırma Gazi Üniversitesi Sağlık Bilimleri Enstitüsü Araştırma Fonu tarafından desteklenen EF.02/ 94-5 nolu araştırma projesinin bir kısmını oluşturmaktadır. 
Anadolu'da geniş bir yayılma alanına sahip olan Linaria türleri "Nevruz otu" adıyla bilinmektedir. Linaria türleri halk ilacı olarak Anadolu'da, Japon ve Hint halk tıbbında yaygın olarak kullanılmaktadır. Antidiyabetik, pürgatif, diüretik etkileri yanında emoliyan ve yara iyi edici özelliklere sahip olmaları nedeniyle çeşitli hastalıkların tedavisinde kullanıldıkları bildirilmiştir (2-4). Ayrıca antiallerjik etkileri nedeniyle ekzema tedavisinde de faydalanılmıştır (5).

Bitkinin kimyasal yapısı üzerinde yapılan araştırmalarda başlıca monoterpenler, diterpenler, iridoitler, flavonoitler ve alkaloitler olmak üzere birçok etken madde grubunun varlığı tespit edilmiştir $(3,4,6-10)$.

Linaria genistifolia ssp. confertiflora üzerinde yaptığımız araştırmaların bir kısmını oluşturan bu çalışmada, bitkinin yaprağından alınan enine kesiti yanında yaprak ve çiçeğine ait toz numunelerinden hazırlanan preparatlarının anatomik özellikleri incelenmiştir. Bulgular fotoğrafları çekilerek tespit edilmiştir (Şekil 1, 2A, 2B, 3, 4).

\section{MATERYAL VE YÖNTEM}

Linaria genistifolia (L.) Miller ssp. confertiflora (Boiss.) Davis (Scrophulariaceae) 21.7.1994 tarihinde Ankara-Konya karayolu üzerinde (35.km) Gölbaşı civarından toplanmıştır. Bitkiden hazırlanan herbaryum örnekleri Gazi üniversitesi Eczacılık Fakültesi Farmakognozi Anabilim Dalı'nda saklanmaktadır.

Numuneler gerekli incelemeler için \% 70'lik etanol içerisinde saklanmıştır. Yapraktan alınan enine kesitler ve toz numunelerin incelenmesi için Sartur ve Kloralhidrat reaktiflerinden faydalanılmıştır. Hazırlanan preparatlara ait fotoğraflar Olympus BHS BH2 araştırma mikroskobundaki mikrofografı cihazı yardımıyla çekilmiştir.

\section{BULGULAR}

\section{Yaprak Anatomisi:}

Linaria genistifolia ssp. confertiflora'nın yaprakları enine keside orta damara ait büyük iletim demeti ve yan damarlara ait küçük iletim demetleri olmak üzere muntazam bir diziliş göstermektedir (Şekil 1 A, IB). Epiderma tek sıralı ve üzeri kalın bir kütikula tabakası ile kaplıdır. Yaprakların uç kısımlarında her iki yüzde de stoma hücreleri, mezofil dokuda kristaller ve kümelenmiş halde nişasta hücreleri bulunmaktadır. Kristaller prizmatik, basit billurlar şeklindedir. Stoma hücreleri biri küçük ikisi büyük olmak üzere üç komşu hücreye sahiptir (Şekil 2A, 2B, 3). 

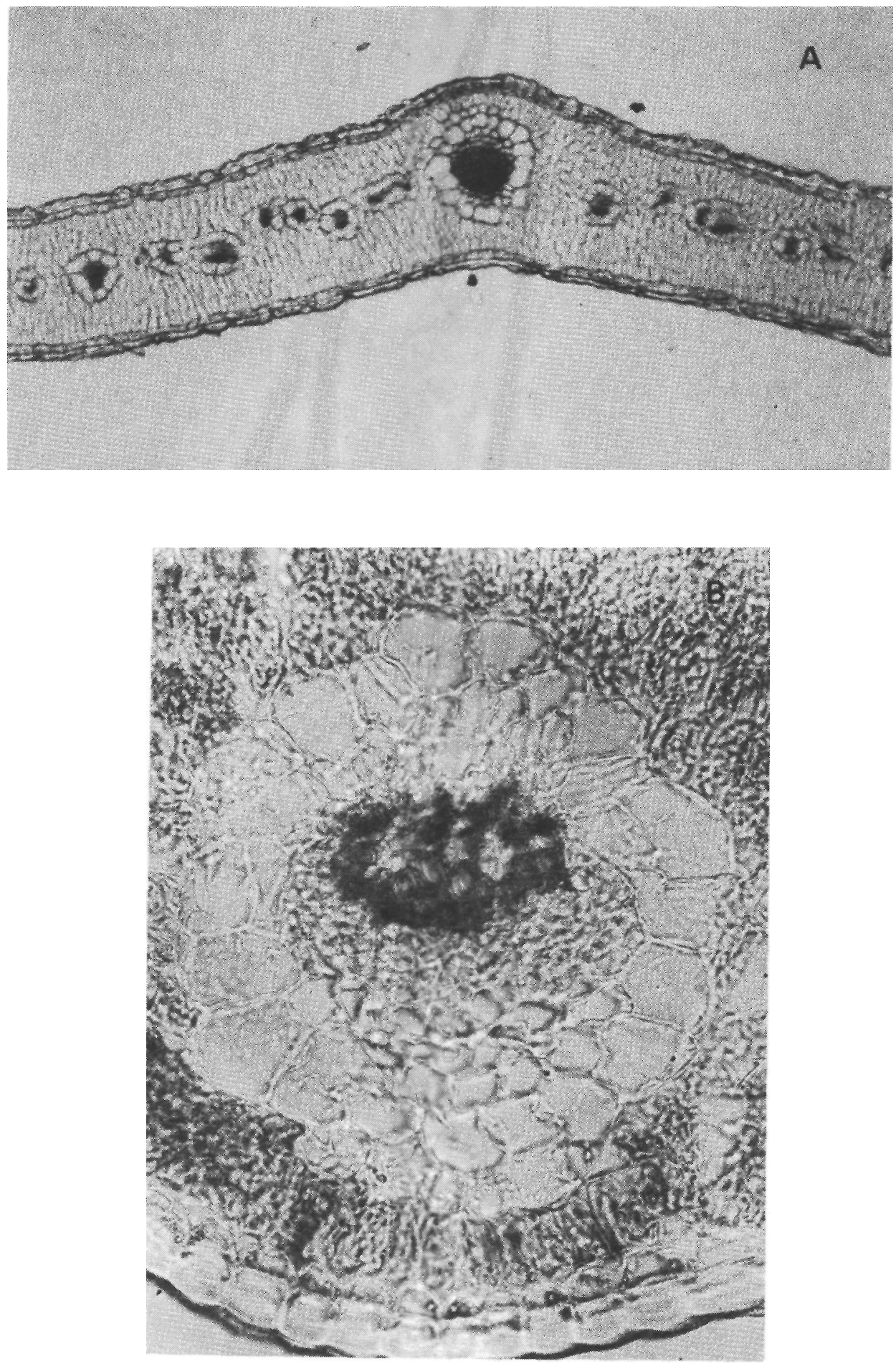

Şekil 1. Yapraktan enine kesit

A. Küçük büyütme altında (x40)

B. Orta damar ve iletim demeti (x200) 

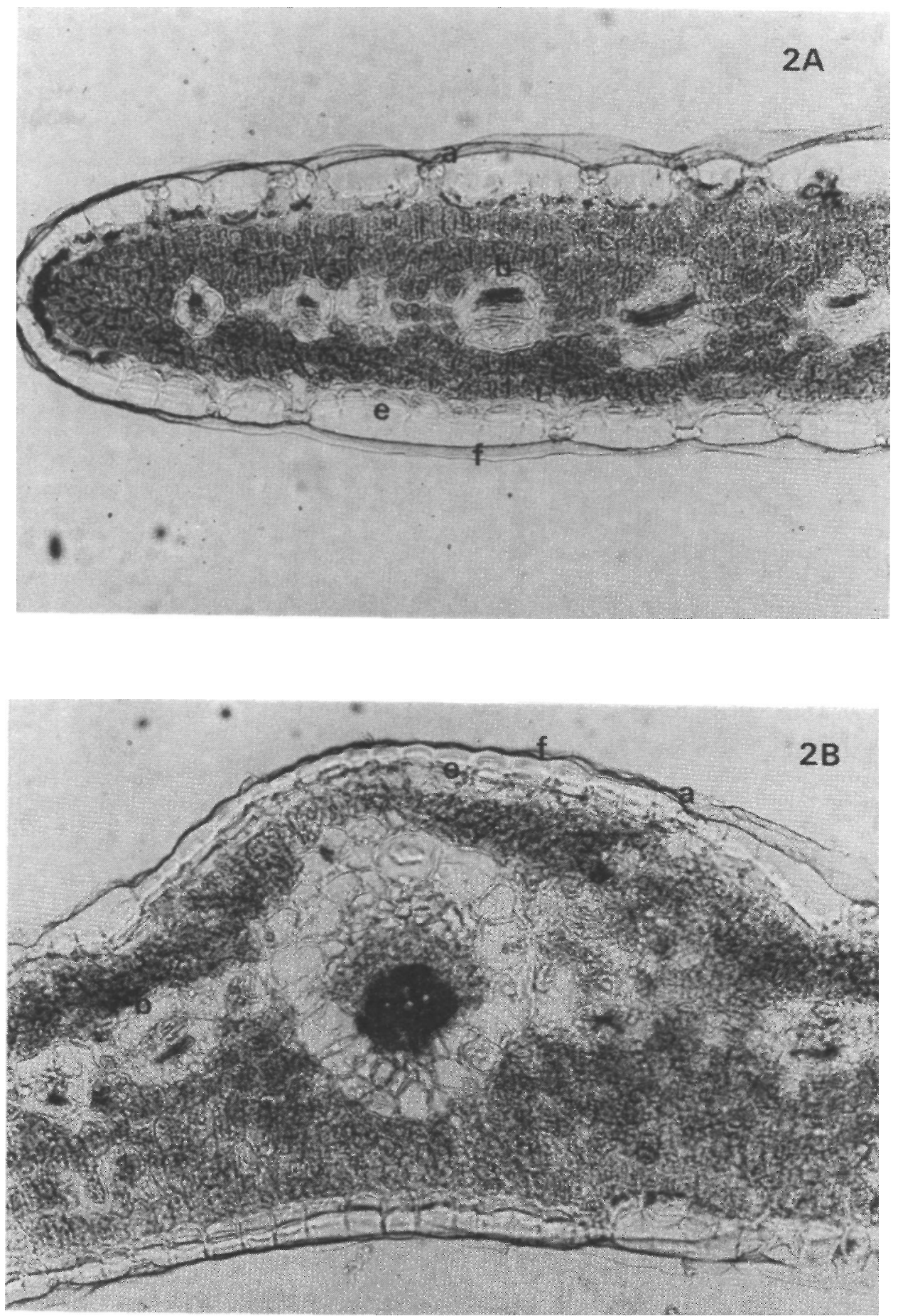

Şekil 2A, 2B. Yapraktan enine kesit (x100)
a. Stoma
d. Nişasta
b. İletim demeti
c. Mezofil parankiması
e. Epiderma
f. Kütikula 

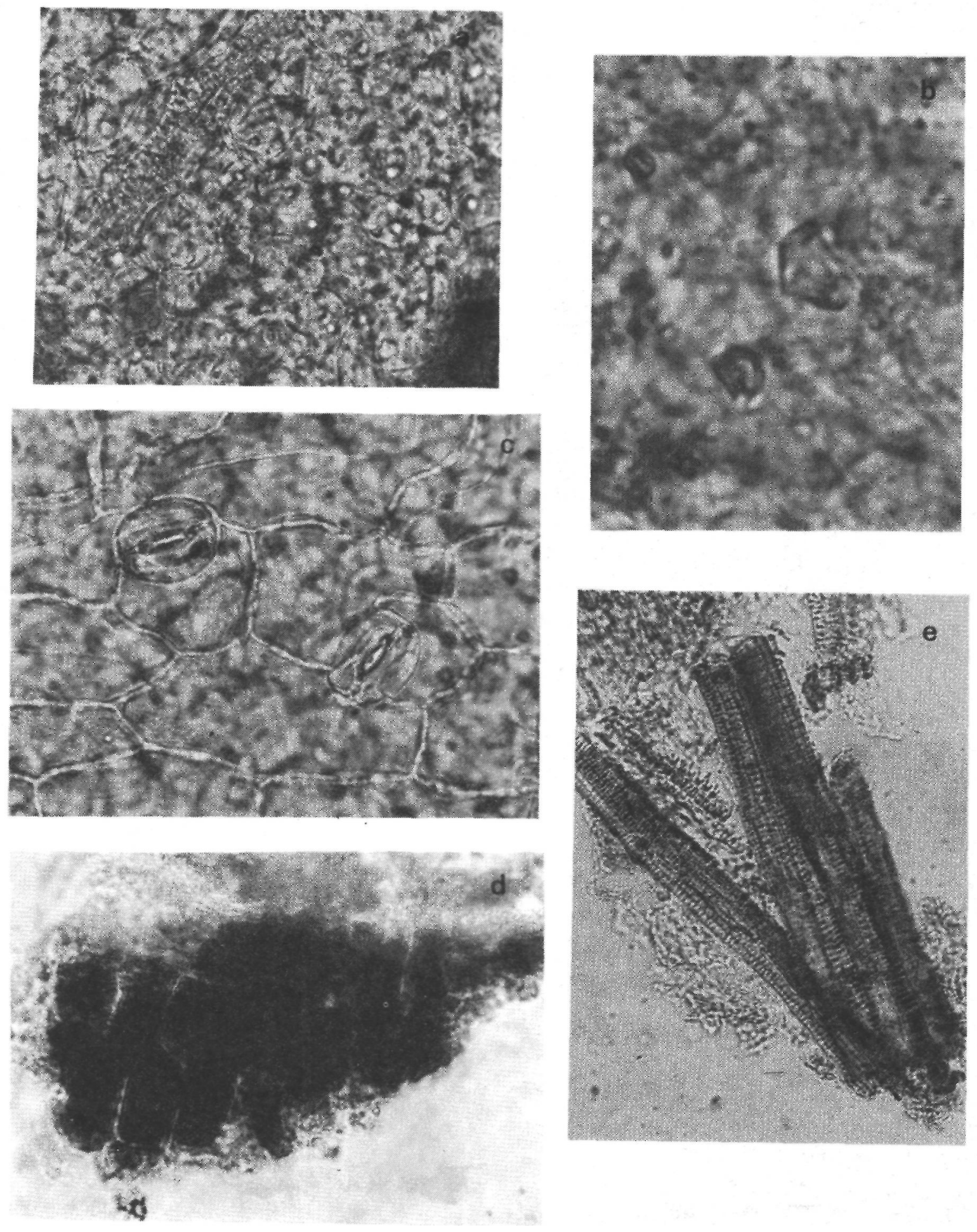

Şekil 3. Yaprak tozu
a. Basit billur (x400)
b. Basit billur (x1000)
c. Stoma ve komşu hücreleri (x400)
d. Parankima ve nişasta (x400)
e. Odun boruları (x200)

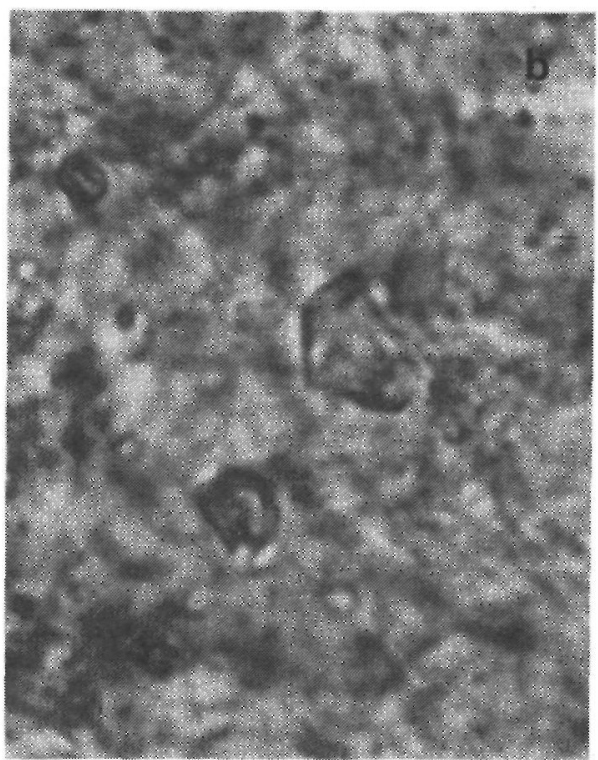




\section{Çiçek Anatomisi:}

Çiçek tozunda yapılan çalışmalarda dalgalı çeperli korolla epiderması, kütikula kıvrımları ve polenler tespit edilmiştir. Korollaya ait dokularda billurlar ve yıldız tüyler karakteristik bulgulardır (Şekil 4).
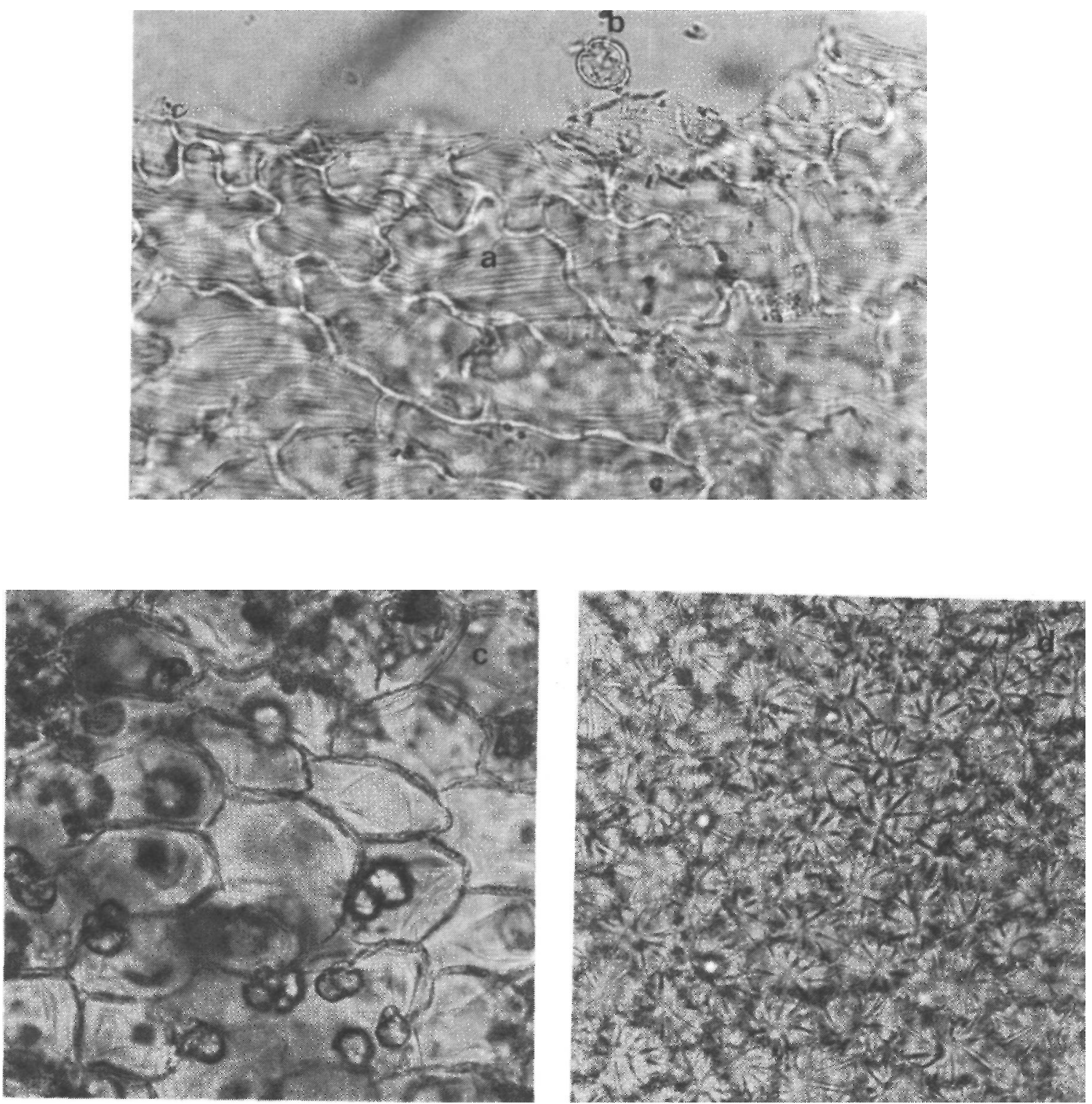

Şekil 4. Çiçek tozu

a. Dalgalı çeperli korolla epiderması (x400)

b. Polen (x400)

c. Korolla hücreleri ve billur (x400)

d. Korolla epiderması ve yıldız tüyler (x400) 


\section{SONUÇ VE TARTIŞMA}

$\mathrm{Bu}$ araştırmada Linaria genistifolia ssp. confertiflora bitkisinin anatomik özellikleri incelenmiştir. İncelemeler sonucunda elde edilen bulgular fotoğrafları çekilerek belirlenmiştir (Şekil 1, 2A, 2B, 3, 4).

Linaria cinsine ait anatomik özelliklerin bazıları literatür bilgisi olarak bulunmakla birlikte (11), Linaria genistifolia ssp. confertiflora bitkisinin anatomik yapısı hakkında herhangi bir bilgiye rastlanmamıştır. Linaria cinsi dahil olmak üzere Scrophulariaceae familyasına ait bazı cinslerde salgı tüyünün varlığı kayıtlıdır (11). Ancak bizim incelediğimiz alttürde salg1 tüyü bulunmamıştır. Literatürde Linaria cinsinin yaprağında küçük ve sık olmayan prizmatik billurların varlığı bildirilmektedir (11). Bizim bulgularımız bu bilgiye uygunluk göstermektedir. Yaprakta sık olmayan küçük prizmatik kalsiyum okzalat kristalleri görülmüştür (Şekil 3). Literatürlerde yer almayan çiçeğe ait anatomik özellikler bu çalışma ile ortaya konmuştur (Şekil 4).

$\mathrm{Bu}$ araştırmayla, kimyasal bileşimi ve biyolojik etkileri üzerinde oldukça fazla çalışma bulunan Linaria türlerinden birisi olan Linaria genistifolia ssp. confertiflora' nın anatomik özellikleri belirlenerek türün daha iyi tanıtılmasına çalışılmıştır.

\section{KAYNAKLAR}

1. Davis, P. H. Flora of Turkey and The East Aegean Islands, Vol.6, University Press, Edinburgh, 654-72 (1978).

2. Baytop, T. Türkiye'de Bitkiler ile Tedavi (Geçmişte ve Bugün), İstanbul Üniversitesi Yayınları, No:3255, Sanal Matbaacılık, İstanbul, 420 (1984).

3. Singh, M., Prakash, L. "A new flavone glycoside and other chemical constituents from Kickxia ramosissima Wall. (Syn. Linaria ramosissima Wall.) (Scrophulariaceae)" Pharmazie, 42(7), 490-1 (1987).

4. Kitagawa, L, Tani, T., Akita, K., Yosioka, I. "Constituents of Linaria japonica. I. Sttucture of linarioside, a new chlorinated iridoid glucoside and identification of two related glucosides" Chem. Pharm. Bull., 21(9), 1978-87 (1973).

5. Dobrescu, D., Cristea, A., Susanu, M. "Experimental pharmacodynamic study of Linaria vulgaris used in folk medicine for the treatment of eczemas" Farmacia Bucharest, 33, 215-20 (1985).

6. Glasby, J. S. Dictionary of Plants Containing Secondary Metabolites, Taylor and Francis Ltd., Burgess Science Press, London, 193 (1991). 
7. Sticher, O. "Isolation of antirrinoside from Linaria vulgaris" Phytochemistry, 10(8), 1974-5 (1971).

8. Harborne, J. B., Valdes, B. "Identification of scutellarein 4'-methyl ether in Linaria aeruginea" Phytochemistry, 10(11), 2850-1 (1971).

9. Harborne, J. B. "Comparative biochemistry of flavonoids. I. Distribution of chalcone and aurone pigments in plants" Phytochemisrty, 5(1), 111-115 (1966).

10. Groeger, D., Johne, S. "Occurence of peganine in Linaria species" Planta Med., 13(2), 182-8 (1965).

11. Metcalfe, C. R., Chalk, L. Anatomy of the Dicotyledons, Vol.11, Clarendon Press, Oxford, 97988 (1965).

Başvuru tarihi : 01.12.1997

Kabul tarihi $\quad: 16.04 .1998$ 